\title{
Cyber-Physical Production Systems in Settings with Limited Infrastructure
}

\author{
Blind Spots and Implications
}

\author{
Bastian Prell ${ }^{1}$, Norman Günther ${ }^{1}$ and Jörg Reiff-Stephan ${ }^{1}$ [https://orcid.org/0000-0003-4176-6371] \\ ${ }^{1}$ Technical University of Applied Science Wildau, Germany
}

\begin{abstract}
During the last decade production innovation was mainly focused on connectivity aspects. The vision of smart factories running on software, that uses collected machine data, has become true but foremost for leading industrial companies in highly developed countries. Apart from these, production can also be found in non-industrialized craft professions as well as in less developed countries. As digitalization does not necessarily require an industrial or developed setting the latter could possibly benefit from it as well. Socio-cyber-physical production systems have been used to describe the interdependencies of linked production systems but usually focus on highly developed regions as well as for industrial applications. This paper lines out similarities and differences for each case, introduces the concept of cyber-physical production systems (CPPS) and its extension to socio-CPPS (SCPPS), which emphasizes the role of human workers in the production environment. The relation between industrial, non-industrial production and innovations is examined. Furthermore, the widening of SCCPS concepts for non-industrial production is discussed.
\end{abstract}

Keywords: Socio-Cyber-Physical Production Systems, Limited Infrastructure, Developing Countries, Craft, non-industrialized, Digitalization

\section{Introduction of Terms and Concepts}

The collective state of the art in production technology defines the market price for each good. The respective technology used by the individual company defines their costs, thus it directly affects their profits: This is why innovation itself is regarded as competitive advantage. Thus, producing companies are constantly on the lookout for innovations that can be used beneficial in a manufacturing context. Cyber-physical production systems (CPPS) are the application of cyber-physical systems (CPS) in production context. That is why the advancements of the last decade regarding information and communication technology (ICT) may revolutionize value creation. Especially availability of sensory equipment and smart software, made it possible to process large quantity of data and support or even make decisions and affect the physical world through actuators [1]. Production processes usually take place in a production system consisting of various machines that can carry out process steps. The digitalization of single machines is wide spread. Whatsoever, relevant benefits can usually only be unlocked, when regarding at least the complete production system or even the whole value creation process [2], [3]. These considerations have led to the concept of CPPS, which this work reviews from a non-industrial perspective.

CPPS have been widely discussed in literature. But even though it is often used as a homogenous concept a unique definition does not exist. Exemplarily the following citations show why the authors found it helpful to formulate a working definition of (Socio-)CPPS while taking existing ones into account but showing deviations explicitly. 
Monostorie [4] (depicted in Figure 1 as a)) formulates CPPS as the combination of manufacturing science and ICT, and therefore as "systems of collaborating computational entities which are in intensive connection with the surrounding physical world and its ongoing processes, providing and using, at the same time, data accessing and data-processing services available on the internet." Meanwhile, Niggemann and Lohweg [5] (b)) state: "A CPPS is a holistic conception of modern, often distributed, production systems: It treats mechanical, computational and external aspects [, that] can only be handled if [it] comes with a set of intrinsic cognitive capabilities such as self-diagnoses, self-configuration, selfoptimization and intelligent user interaction." Thiede et al. [6] (c)) emphase the valid aspect, that CPPS "consisting of a physical component, as well as a virtual component, [... are] connected to the employee. A technology containing computational and physical capabilities combined with the possibility of human machine interaction." Similarly, Rudtsch et al. [7] included prediction and almost real-time aspects (e)).
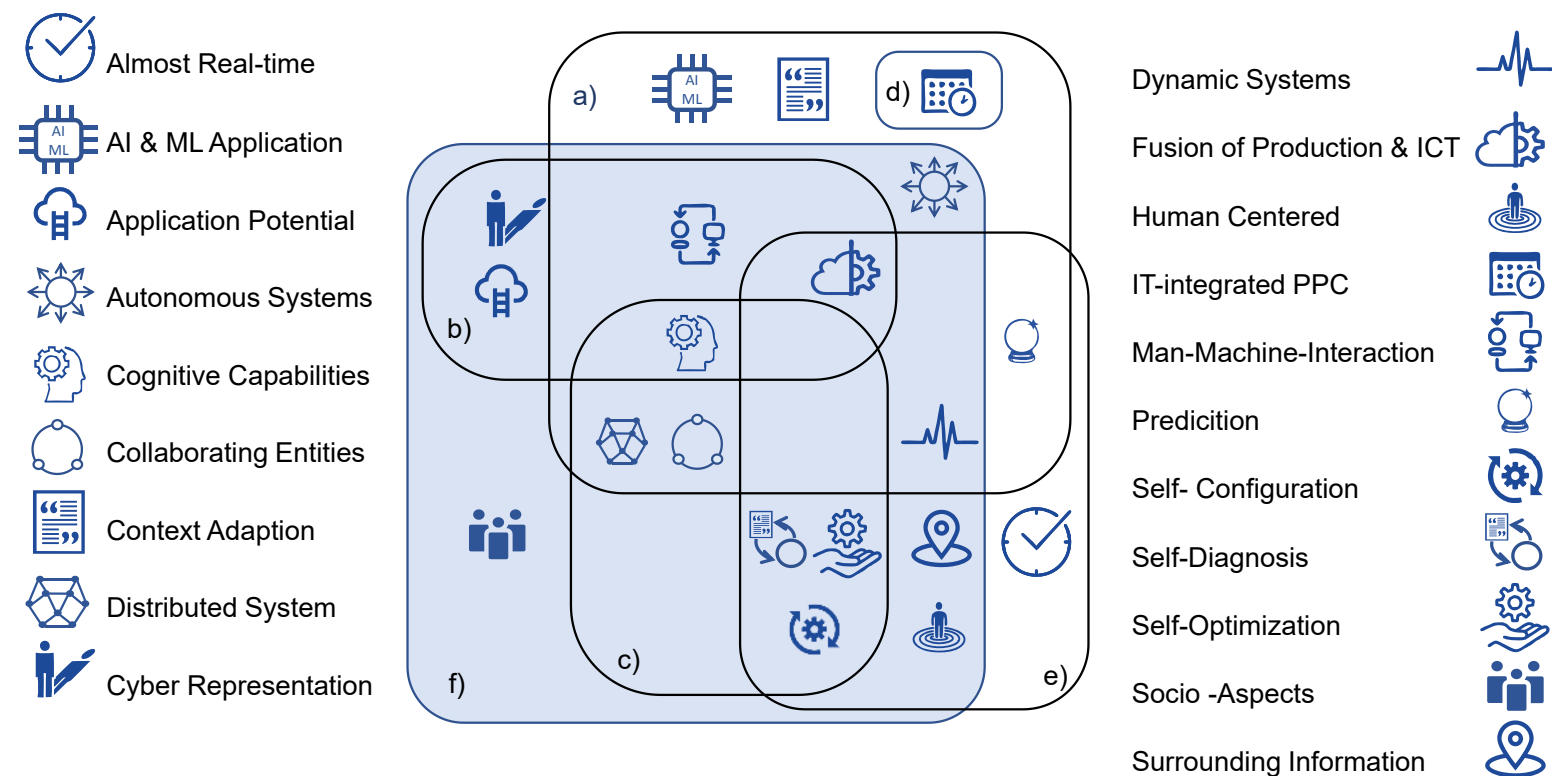

Figure 1. Defining Aspects of CPPS - usually related but not identical.

The working definition can be observed in the box $\mathrm{f}$ ), and can be formulated as follows:

A CPPS is characterized by a virtual representation of the physical production means, which replicates the distributed entities and is enriched by surrounding information in order to unlock manifold application potential (e.g., self-configuration, self-diagnosis, selfoptimization). Those systems are usually dynamic and therefore complex, the system itself needs to provide cognitive capabilities to achieve the goal of collaborating, autonomous entities. When several of those entities are human workers served by the technology, who then can rather be described as the user, one can speak of a socio-cyber-physical production system (SCPPS).

Thus, each SCPPS is a CPPS but not vice versa.

\section{Motivation}

The history of modern society has been closely linked to successful usage of innovations in production. Every time technology had advanced production potency, it was accompanied with major cultural changes, that in retrospective formed industrial revolutions, as they are depicted in Figure 2. Initiated by steam engines, heavy tasks could be performed by mechanical equipment, enabling the mechanical loom and thus the blossom of textile industries in Europe, making railway commuting necessary as well as available and also laying the foundations of the suburban housing system, e.g., in London. Soon steam engines were replaced by electric motors, that eased the constriction of central drives and allowing 
the first value stream-oriented production lines, like the Ford Model T production. Dominating conveyor belts thus paved the way for the automotive society we take for granted nowadays. Automation then took over more complex motion sequences, enabling mass production for more and more product types, announcing the era of consumption (e.g., household appliances penetration rising esp. from the 1970s on [8]). These developments finally lead to the current informational interlinking of production means, for smoother transfer and creation of required data, information or even knowledge. Each of the industrial revolutions of the past had brought social change by the newly required work, qualifications and education but also by serving unmet demands [9].

Digitalization and Industrial Internet of Things are trending terms within the scientific but also practical production research community. Even first applications of artificial intelligence have proven to work beneficial. A more recent spin of this research area has proclaimed the human centered production system and thereby forecasting the upcoming change of paradigm [10], [11]. The change of mass production can be observed: Individualization, human-robot collaboration, sustainability, robotics and bionics are already found in some factories. SCPPS can be used to conceptually merge the paradigm shift with these nowadays linked production facilities [12].

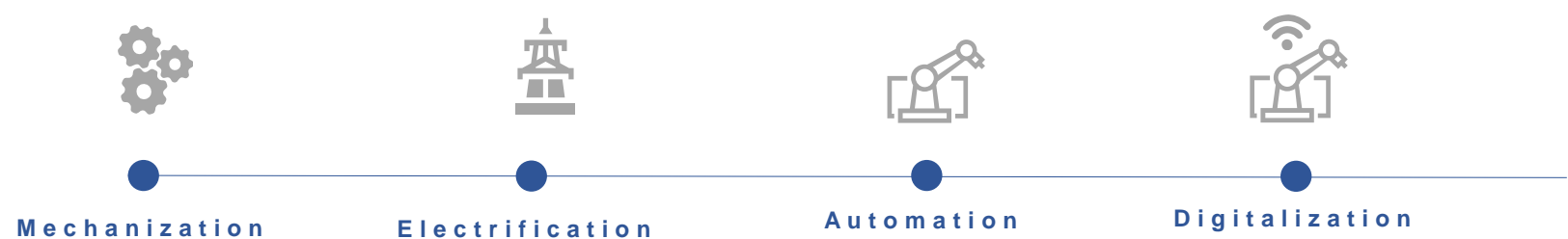

Figure 2. Industrial Revolutions - so far.

As the digitalization of production means can be viewed as ongoing, its foreseeable implications as well as the blind spots regarding non-industrialized production shall be addressed by examining the research question, presented in the following section. The investigation will be structured by sections, each addressing one of those research questions. Hereafter, the findings are illustrated exemplarily for three scenarios. The paper concludes with a summary and outlook on further research.

\section{Research Questions}

The observed mega trend of individualization and flexibility in production has brought up the idea of an ideal industrial process with a batch size of one. CPPS are often seen as the technological base to achieve these goals. Batch sizes of one whatsoever have been a characteristic of non-industrial production. The first research question of this paper is therefore:

A) What are the implications of industrial and non-industrial production, both converging to a batch size of one?

CPPS have usually been viewed as a concept applying for industrial production, while focusing on developed (usually also industrialized) countries. The concepts implications shall be examined for non-industrial branches or regions by investigating the second research question:

B) Is the implicit focus of CPPS on industrial production justified?

\section{Addressing Batch Size Convergence}

When considering differences, similarities and convergences between producing structures in industrial and non-industrial context their origins as well the context of the corresponding demands needs to be reviewed. 
Bulk production had been made feasible by industrialization from the $18^{\text {th }}$ century on. Nonetheless, the population's demand for consumption consists of both, products well suited for mass production and those that are less suitable. Therefore, non-industrial production remained predominant kind of manufacturing for certain produce, that proved not suitable for mass production for the respective state of the art. Whatsoever, innovations have widened the capabilities of mass production (as illustrated in Figure 3), but also enabled extended overall consumption. Therefore, a distinctiveness of production volume - both per capita as well as generally - between mass production and non-industrial production can be assumed.

Innovations

Figure 3. Relation between Mass Production, Innovation and Non-Industrial Work.

\section{Craft Production}

Generally, craft production is associated with craftspeople producing:

- $\quad$ artisan unicums (e.g. goldsmiths making jewelry),

- individualized utility produce (tailors, cabinet makers)

- construction site dependent / shifting serial work (tilers, carpenters)

- on-site/ off-site services (car / service mechanics)

- etc.

A similarity of these examples can be seen in the usually high degree of individual requirements that need to be met: Whether it's the fitted measurements of a cabinet, the specific state of a building site or the error search at a particular car. Also, the ambivalence of assigning such jobs either to the manufacturing or the service sector becomes apparent. According to Hipp, unambiguous definitions seem hard to formulate [13]. Nonetheless, for the sake of this paper all produce generating activities shall be included when speaking of production.

In certain craft branches, especially in metal fabrication, shop floor layouts resemble those found in factories. The same holds true for the division of work. Therefore, such crafts, e.g., metal workers or welders, shall be excluded from the crafts definition for this paper, even though these professions are listed by the German chamber of crafts.

\section{Industrial Production}

Formed by the mentioned four industrial revolutions (Figure 2), industrial production came a long way from mass production, coping with serial production and is currently advancing towards individualization.

Traditionally, car manufacturers are leading innovators in Germany. Cars are usually produced in series, but different configurations that the customer can choose from can easily build up to more than 1000 variants for each manufacturer. Many of those individual configurations whatsoever only differ in non-essential qualities such as color mix or rim style, while major differences are grouped by modular platform strategies. Apart from these few different models, the observed individualization can be grouped as pseudo-individualization. More recently soft-individualization has been emerged, which describes that the functionality is built in every product but only activated when the customer choses so by buying it. Another example can be found with sneakers that can be configured by the customer regarding their color mix and stitching [14]. These mass customization branded approaches have in common, that individualized products shall be offered at costs, usually related with mass production [15]. 


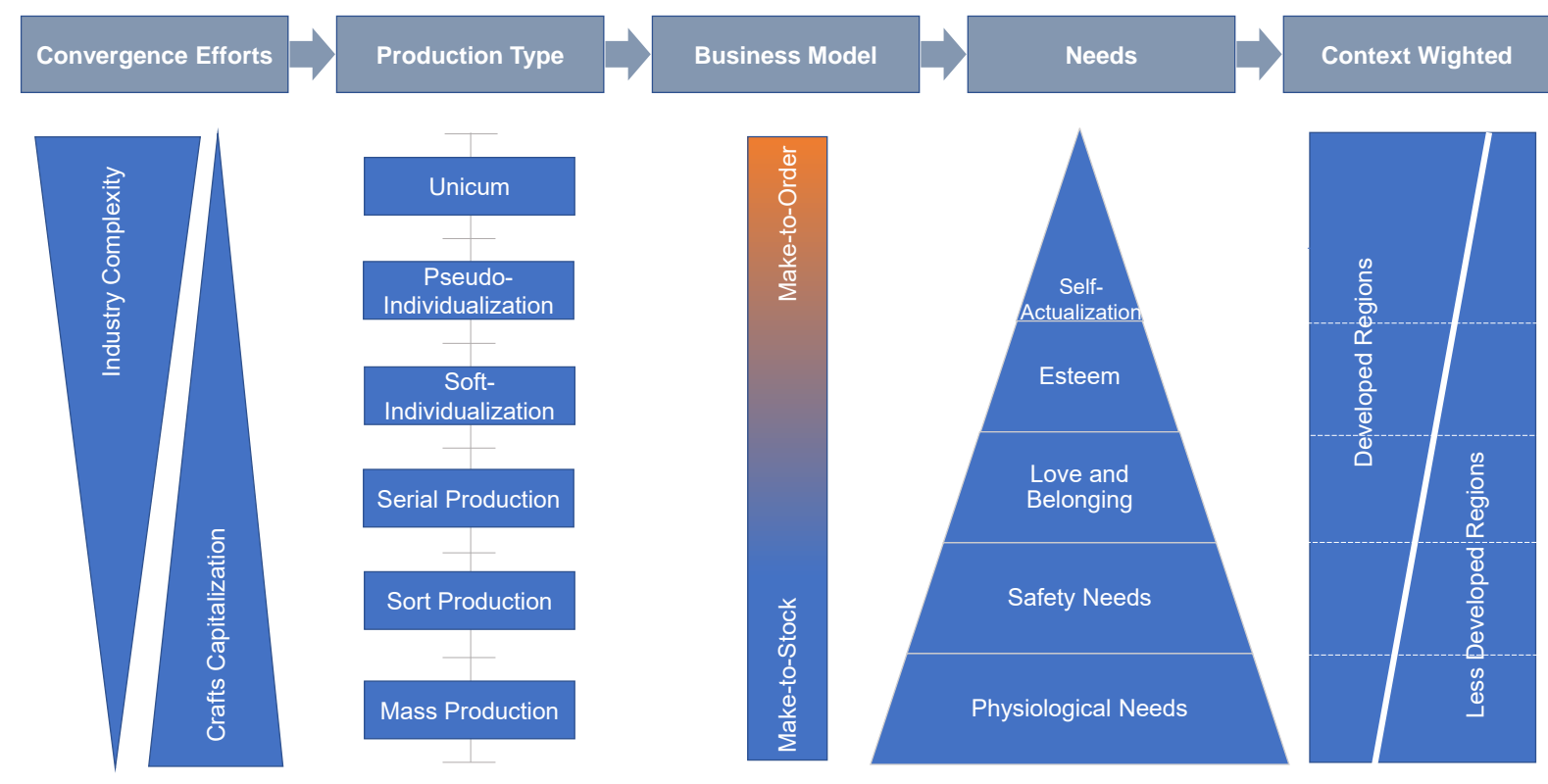

Figure 4. Convergence Aspects from Production and Demand Perspective.

\section{Business Model, Needs and Demand}

Figure 4 depicts the relation between the capability in industrial production to allow individualized production and the corresponding complexity. Vice Versa craft branches need to be capitalized, following industrial examples, if they were to target series or mass product markets. Inherently differences can be - generally speaking - observed for business models: While individualized products are self-evidently only manufactured for the respective order, mass products are usually constantly produced, without being directly linked to particular orders. Fluent transitions can be observed, for example when certain semi-finished products are pre-fabricated and stored until they are assembled according to a certain order.

Production should target demands. Demands are market manifested needs that can be structured accordingly to what is known as Maslow's pyramid of needs scheme [16], [17]. This pyramid scheme by its form and arrangement displays, that the needs on top build up on those below. Those lower needs are also wider and translate more directly into materialistic wants. Therefore, industrial production, with its high output rates seems a reasonable production structure to meet these, so called deficiency needs. Higher needs like esteem or self-actualization are usually seen to be incompatible with the value adding work in the industrial sector [18]. This might be untrue for some industrial jobs and employed individuals, partially due to union backed attempts of purpose loading, but holds true in general [19].

The purchase of individualized goods cannot sustainably compensate for an alienated work environment. SCPPS therefore could approach this by empowering people within the industrial sector to find meaning and purpose in their work. This could be reached by supporting technology that takes over repetitive tasks and supplies information needed to understand the necessity of tasks to allow the worker to mentally participate in the value creation process. The approach of considering the human as a social entity with respective needs may be the next challenge for production technology. On the contrary, technology had been used to some extend to restrict workers alternatives of actions in order to enforce industrial motives and coordination [20]. Furthermore, the implementation of such SCPPS will be confronted with the common obstacles of reorganizations, as it affects not only production but potentially complete business models [20], [3].

Craft professions offer better possibilities of identification and self-actualization [21]. Unicums or small series as well as individualized produce had been their retreat, where cost cutting industrial production was not possible (not economically or technologically feasible). 
Even though, complete redundancy of craft professions won't be likely, a gradual shift, abstractly displayed in Figure 3, can already be experienced. Given the advantages of productive crafts for meeting higher needs for customers by individualized goods, as well as for workers by higher degrees of self-actualization and the social commitment to preserve such traditions [22], [23], it seems worth to look for fields of application for novel technologies such as SCPPS, also in craft professions.

Another perspective can be gained by putting these opposed advantages and disadvantages in the context of industrialized (what is usually meant by the term developed countries) and less developed regions, in that manner. On the one hand the population in industrialized societies can be assumed to have less urgent needs from the bottom categories of the needs pyramid, because most physiological needs and also those for materialistic safety have been met by industrial (over-) production. Populations of nonindustrial countries on the other hand have not been confronted with extensive alienation from work, and therefore their self-actualization is not affected by these structures but more so by less than sufficiently met needs, from the need pyramids bottom [24].

Not without wit, this can be expressed in short by an African proverb, stating:

"You have the watches; but we have the time."

\section{Addressing SCPPS Focus on Industrial Production}

This section will unfold, why CPPS have been focused on industrial application for the most part. Here after, the validity of the antithesis, that a non-industrial focus is I) possible, II) relevant, and III) reasonable, is shown.

Digitalization in production foremost has been regarded from the driving forces point of view: Mainly large companies, that can build up on most recent automation technologies and acquire implementation services from experts. Naturally, by the way it emerged, digitalization of production usually considers highly automated facilities combined with high labor costs.

I) Digitalization whatsoever does not necessarily need automation but brings the opportunity to skip, some of the steps usually mentioned as industrial revolution [25]. Thus, breaking with rules of the well acknowledged decomposition of the automation hierarchy the automation pyramid [4].

II) Apart from industry, production also takes place in non-industrialized settings: On the one hand a non-neglectable part - $12 \%$ for Germany - of production is carried out by craftspeople [26]. On the other hand, developing countries are characterized by their mostly non-industrialized creation of value. Non-industrial hereby means either the absence of division of labor (as it can also be observed for craft professions) or less capitalization as might be commercially feasible. Nevertheless, for large parts of the population in developing countries the potential gain in standard of living from any production efficiency increase is much higher than a similar measure would allow for in an industrialized setting. Furthermore, crafts keeps artisan knowledge alive and is widely seen as a cultural heritage, worth to sustain [22].

Apart from the experienced neglection of both aspects in CPPS conceptions so far, further similarities can be observed between productive crafts and value creation in lessdeveloped regions. While industrialization has unbound workplace and family ties in most developed countries by paid labor, family businesses are especially often found in craft branches. The same holds true for most developing countries, where knowledge of workmanship is passed on to the next generation. Especially when economic security during retirement relies on the succeeding descendants. For both parties a well-developed awareness for traditions can be observed.

Even though, machines are widely used by craftspeople in industrialized regions, their professions are usually still known as physically challenging. Meanwhile, a lack of production means in developing countries leads to higher shares of manual work. 
Nevertheless, broadening recent SCPPS-modelling approaches for those alternative settings with limited infrastructure seems increasingly relevant. SCPPS can be used to conceptually consider the strong focus on human interactions, which herein occur in a much more characteristic manner than they do for an industrial setting.

III) In order to make these considerations about reasonable SCPPS integration more conceivable, value creation was modeled in Figure 4 for three scenarios: The left reflects the usually highly automated, high labor cost scenario of an industrialized country. Meanwhile the middle presents the craftspeoples approach of value creation for a functionally similar product. Concluded by right, representing a less developed region.

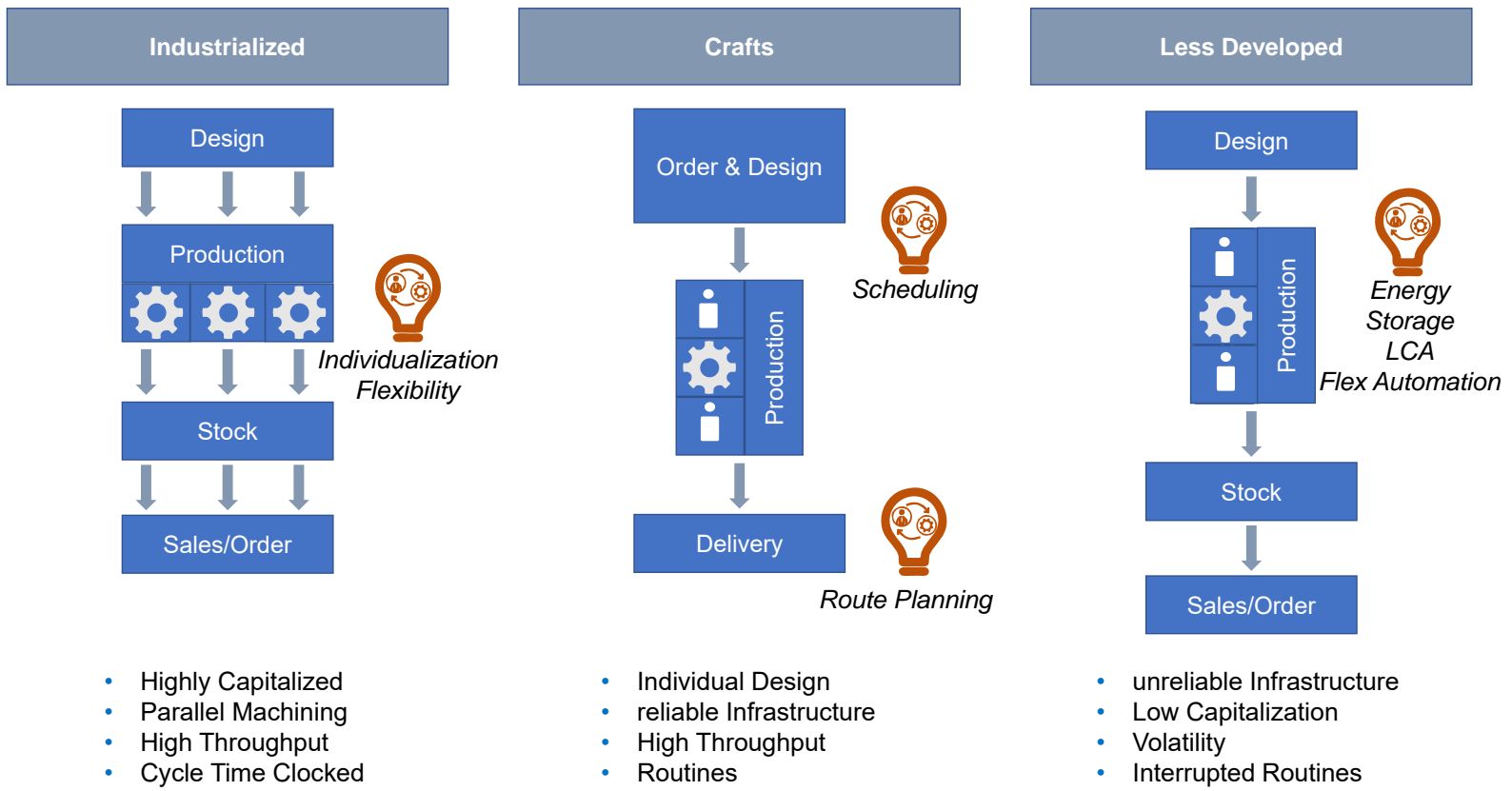

Figure 5. (S)CPPS Usage scenarios.

As mentioned, potential industrial use cases for CPPS or respective SCPPS are dominated by enabling individualization and product flexibility, as well as process flexibility. Such production is usually clocked by corresponding cycle times in order to synchronize parallel machining, allowing high throughputs, that are needed for the amortization of machinery. Productive crafts can easily be imagined to conclude individual contracts. The order is then produced usually with man power of the executing personal as bottle neck, while machinery is mostly not working full capacity but is frequently confronted with usage peaks and other organizations hazards [27]. SCPPS could help to schedule orders, so that synergies can be used and peaks of machine usage are avoided, while waiting times can be minimized. Production can follow the contract because of reliable infrastructure. Stock of raw material can easily be restored, a more or less steady flow of sales can be achieved through distance selling. Most important for a successful implementation is the ease of use. For less developed regions, in which infrastructure is insufficient, a make-to-stock model seems to be the pragmatic path, as individualization is not so advanced and it offers a steadier capacity usage. Furthermore, scarce capital will be rather be used for machinery than for floating assets, preventing large stocks and steady utilization of machinery. Bottle necks can mostly be traced back to the insufficient infrastructure affecting the supply chain. Once input factors are accumulated, machinery briefly becomes the bottleneck, as labor is usually flexible available at low cost. Energy is an input factor that is easily neglected in the western hemisphere. For regions heavily affected by shortages or low degrees of availability, this becomes another determinant for production. Autarkic systems as proposed by ReiffStephan et al. can level such effects out [28]. Whereas autarkic systems than need to be user friendly for usage as well as maintenance -a speaker, signaling when production is energetically feasible could benefit the mentioned system. Same holds true for low cost 
automation (LCA), as a digital image can support intuitive reconfiguration, e.g., by a flow programming scheme, like the popular node-RED [29].

\section{Conclusion and Summary}

Competition between innovation driven extension of industrial production towards individualized produce and productive crafts may intensify. CPPS could be seen as a major driver of this development. Nevertheless, crafts offer a unique production structure that is unlikely to be made completely redundant and "producing" self-actualization for the people carrying out the profession, which industrial structures are less capable of. Both sectors could benefit from SCPPS in this regard. In a rather abstract manner starting points of SCPPS implementation have been shown for the discussed scenarios. Furthermore, it became clear that SCPPS are not solely a technical solution but during development and implementation sociological aspects embedding the stakeholders need to be considered as well.

Further research could benefit from exemplarily implementation and empirical observations that ought to support the deduced statements.

\section{Acknowledgement}

This publication was made possible through the funding of the $\mathrm{PhD}$ program Innovation and Career Center - Integrated Engineering by the state of Brandenburg's Ministry of Research, Education and Culture (Germany).

\section{References}

[1] Hermann M, Pentek T, Otto B. Design principles for industrie 4.0 scenarios. Proceedings of the Annual Hawaii International Conference on System Sciences. 2016;2016-March:39283937. https://doi.org/10.1109/HICSS.2016.488

[2] Buer S, Strandhagen JO, Chan FTS. The link between Industry 4.0 and lean manufacturing: mapping current research and establishing a research agenda. International Journal of Production Research. 2018;56(8):2924-2940.

https://doi.org/10.1080/00207543.2018.1442945

[3] Gassmann O, Csik M. Change a Running System. In: Die Kunst der Innovation. Gabler Verlag; 2012:41-49. https://doi.org/10.1007/978-3-8349-7188-3 3

[4] Monostori L. Cyber-physical production systems: Roots, expectations and R\&D challenges. Procedia CIRP. 2014 Jan, 9-13. https://doi.org/10.1016/j.procir.2014.03.115

[5] Niggemann O, Lohweg V. Proceedings of the AAAI Conference on Artificial Intelligence. 2015 Mar.

[6] Thiede S, Juraschek M, Herrmann C. Implementing Cyber-physical Production Systems in Learning Factories. Procedia CIRP. 2016 Jan, 7-12.

https://doi.org/10.1016/j.procir.2016.04.098

[7] Rudtsch V, Gausemeier J, Gesing J, Mittag T, Peter S. Pattern-based business model development for cyber-physical production systems. Procedia CIRP. 2014 Jan, 313-319. https://doi.org/10.1016/j.procir.2014.10.044

[8] Cabeza LF, Ürge-Vorsatz D, Ürge D, Palacios A, Barreneche C. Household appliances penetration and ownership trends in residential buildings. Renewable and Sustainable Energy Reviews. 2018 Dec 1;98:1-8. https://doi.org/10.1016/j.rser.2018.09.006

[9] Das große Ding: Handwerk 4.0 Wie Betriebe und Beschäftigte erfolgreich den digitalen Wandel meistern Die Gewerkschaft für das Handwerk,. IG Metall; 2015. 
[10] Günther N, Reiff-Stephan J. Future Skills für die Produktion von Morgen. AALE 2019. 2019.

[11] Prescher T, Hellriegel J, Schön M, Baumann A, Heil M, Schulz F. Digitalisierung im Handwerk als Lernprozess fördern. CEUR Workshop Proceedings. 2016;1669(DeLFI):209215.

[12] Günther N, Reiff-Stephan J. Prescriptive Education im Zuge der Industrie 5.0. In: Jäkel J, Thiel R, eds. AALE. Leipzig: VDE Verlag; 2020:315-320. https://doi.org/10.1007/978-3$\underline{642-51663-4 \quad 17}$

[13] Hipp C. Innovationsprozesse im Dienstleistungssektor: Eine theoretisch und empirisch basierte Innovationstypologie. Physica-Verlag HD; 2000.

[14] Gracia VB, Winkelheus K. The Next Revolution in Mass Customization : An insight into the sneaker market . La Próxima Revolución en la Personalización Masiva : Una visión en el mercado de las zapatillas de deporte .. 2016;4(June):85-104.

[15] Saldivar AAF, Goh C, Chen WN, Li Y. Self-organizing tool for smart design with predictive customer needs and wants to realize Industry 4.0. 2016 IEEE Congress on Evolutionary Computation, CEC 2016. 2016;:5317-5324.

https://doi.org/10.1109/CEC.2016.7748366

[16] McDermid CD, McDermid, D. C. How Money motivates Men. Business Horizons. 1960;3(4):93-100.

[17] Maslow AH. A theory of human motivation. Psychological Review. 1943 Jul;50(4):370396. https://doi.org/10.1037/h0054346

[18] Schumann M. Industriearbeit zwischen Entfremdung und Entfaltung. SOFI-Mitteilungen. 2000;28(2000):103-112.

[19] Dörre K. Gewerkschaftseliten nach 1945 - Kontinuität und Wandel der

Führungsgruppen deutscher Gewerkschaften: Das wiederbelebte Interesse an den gewerkschaftlichen Führungsgruppen. . Accessed 2006.

[20] Picot A, Dietl H, Franck E, Fiedler M, Royer S. Organisation : Theorie und Praxis aus ökonomischer Sicht. Stuttgart : Schäffer-Poeschel; 2012.

[21] Blankenberg A, Binder M. Göttingen: Volkswirtschaftliches Institut für Mittelstand und Handwerk an der Universität Göttingen (ifh); 2020. https://doi.org/10.3249/2364-3897-gbh-42

[22] Lahner J. Innovationsprozesse im Handwerk, Göttinger handwerkswirtschaftliche Studien, No. 69. Duderstadt: Mecke Druck und Verlag; 2004.

[23] Dörre K. Industrie 4.0 - Neue Prosperität oder Vertiefung gesellschaftlicher Spaltungen? Sechs Thesen zur Diskussion. 2016;:15.

[24] Ullrich O. Das Produktivistische Weltbild..

[25] Welzbacher C, Pirk W, Osterheimer A, Bartelt K, Bille J, Klemmt M. Digitalisierung der Wertschöpfungs- und Marktprozesse - Herausforderungen und Chancen für das Handwerk. Eine Vorstudie im Rahmen der Konzeption eines Demonstrations- und Kompetenzzentrums im Handwerk. 2015;:49.

[26] Zentralverband des deutschen Handwerks. Kennzahlen des Handwerks. . Accessed 2018.

[27] Kazaz A, Ulubeyli S, Acikara T, Er B. Factors Affecting Labor Productivity: Perspectives of Craft Workers. Procedia Engineering. 2016 Jan, 28-34.

https://doi.org/10.1016/j.proeng.2016.11.588

[28] Reiff-Stephan J. Solar power in product development. In: Reiff-Stephan J, Amouzou K, Adanlete A, eds. 1st German-West African Conference on Sustainable, Renewable Energy Systems SusRes : 1st July 2020 - Kara, Togo. Wildau: TH Wildau; 2020:55-65. 
[29] Gokalp MO, Kayabay K, Akyol MA, Eren PE, Kocyigit A. Big data for Industry 4.0: A conceptual framework. Proceedings - 2016 International Conference on Computational Science and Computational Intelligence, CSCI 2016. 2017;:431-434.

https://doi.org/10.1109/CSCI.2016.0088 